\title{
TETANUS: A CASE REPORT
}

Sreelatha P1 , Shyam P2, Venkata Umakanth U. K ${ }^{3}$, Saswati Chattopadhyay4, Raja Mukherjee ${ }^{5}$

\section{HOW TO CITE THIS ARTICLE:}

Sreelatha P, Shyam P, Venkata Umakanth U. K, Saswati Chattopadhyay, Raja Mukherjee. "Tetanus: A Case Report". Journal of Evolution of Medical and Dental Sciences 2014; Vol. 3, Issue 44, September 15;

Page: 10846-10849, DOI: $10.14260 /$ jemds/2014/3414

ABSTRACT: Clostridium tetani is the causative agent of Tetanus. The aim was to detect the presence of Clostridium tetani in a case of suspected Tetanus in a 40 year old male who had history of handling a a thorn injury in the agricultural field 15 days ago. The patient presented with spasm of all the limb muscles and Lockjaw of 2 days duration together with history of convulsions for the last 3 days. Bits of tissue were collected from the necrotic depth of the wound abscess and were analyzed. Clostridium tetani was isolated. A diagnosis of Tetanus was made and the concerned authority was immediately notified. The patient was successfully treated with complete recovery. An early diagnosis of TETANUS is significant because it can help the clinician in early management and prevention of development of terminal respiratory failure and death.

KEYWORDS: Clostridium tetani, Tetanus, Lockjaw, convulsions.

INTRODUCTION: TETANUS is a neurological disorder, common in the rural areas, in warm climates and among males. Most cases of it follow an acute penetrating skin injury. The injury may be major but often it is so trivial that medical attention is not sought. The condition is characterized by increased muscle tone and spasmodic contractions due to Tetanospasmin, a powerful exotoxin produced by Clostridium tetani, a ubiquitous obligate anaerobic gram positive organism.

Its spores are in soil and in the feces of humans and animals ${ }^{1}$. Despite the passive and effective immunization since1893, it is still a significant health problem in the developing world. There are more than 800,000 deaths due to tetanus each year in the world ${ }^{2}$. The incidence of tetanus is between 500,000 to one million cases per year worldwide. ${ }^{3}$

CASE HISTORY: A 40 yrs. old male was admitted to our hospital with chief complaints of spasms of all limb muscles and jaw discomfort and inability to open his mouth fully for 2 days. The patient also had muscle pain first in the upper limbs and then in the lower limbs, together with muscles stiffness and difficulty to swallow. The spasms were of gradual onset .He gave the history of repeated convulsions for the last 3 days.

He was a farmer and suffered a thorn prick in the agricultural field 15 days ago for which he was treated by private practioner. The patient had no history of medical or surgical procedures, had no known allergies, and was not taking any medications. There was no history of any childhood vaccinations. He was neither a diabetic nor a hypertensive and had enjoyed apparent good health before the illness.

GENERAL EXAMINATION: On examination, the vital signs were stable. Temperature was $37.5^{\circ} \mathrm{C}$ oral. The patient was irritable, restless and was unable to communicate because of trismus with a Glasgow Coma Scale score of 15/15. A head and neck examination revealed nuchal rigidity and bilateral submandibular lymphadenopathy. 
There was no opisthotonus. On physical examination, there was a wound with diameter $2 \times 3$ $\mathrm{cm}$ on the left sole with no discharge.

Pulse rate -120 / min.

Respiratory rate - 22 cycles /min.

Blood pressure - 130/80 mm Hg

SP02 - 96\% @ room air

Heart - S1, S2 normal.

Lungs were clear.

CENTRAL NERVOUS SYSTEM EXAMINATION: Deep tendon reflexes present. Planters were flexor in type. Neck stiffness is present. All cranial nerves are normal. CSF findings were normal.

\section{LABORATORY INVESTIGATIONS:}

Complete hemogram - normal counts, sero negative for HIV

ESR - $20 \mathrm{~mm} \mathrm{Hg} / 1 \mathrm{Hr}$.

Blood sugar - normal.

Serum urea, creatinine - normal

Liver function tests and serum electrolytes - within normal limits.

PO2 - 40 mm Hg. PCO2 - 30mmHg pH- 7.2

Based on the clinical features like trismus, tonic spasms of limb muscles, neck stiffness, convulsions, the case was provisionally diagnosed as a case of tetanus. Bits of tissue from the necrotic depth of wound were excised and transported to the laboratory in Thioglycollate broth .It was subjected to both aerobic and anaerobic cultures in blood agar and Mac Conkey agar and incubated at $37^{\circ} \mathrm{C}$ for 24 hours.

Aerobic culture revealed absence of any growth. The material inoculated in one half of blood agar plate and incubated anaerobically in agaspak jar. The material was also inoculated into 3 tubes of Robertson cooked meat broth, one of which was heated to $80^{\circ} \mathrm{C}$ for 15 minutes, the second for 5 minutes and the third tube left unheated. The purpose of heating for different periods was to kill vegetative bacteria which develop from the germinating spores.

Blood agar plates incubated in the Gas pakjar showed swarming growth of Clostridium tetani on the third day which was detected on opposite half of the plate. Gram stain was done and observed under the microscope which showed typical drum stick bacilli. Subcultures from the Robertson cooked meat broth also showed swarming growth of Clostridium tetani .Confirmatory test was done by swarming inhibition test by adding anti-tetanus serum to the half of the blood agar plate. Thus the organism isolated was confirmed to be Clostridium tetani.

MANAGEMENT: The patient was admitted to ICU and based on clinical features a provisional diagnosis of tetanus was made. Tetanus toxoid and antibiotics like injectionAmikacin-500mg I.V. 12 th hourly for 5 days and injection Ceftriaxone + Sulbactum - $1 \mathrm{gm}+250 \mathrm{mg}$ OD for 7 days was given.

After the confirmatory diagnosis, human anti-tetanus immunoglobulin --single dose of 5000 I.U. intramuscularly was administered to the patient. The patient was intubated and connected to ventilator. Muscle relaxants and anti-epileptics were also given .He recovered and extubation was done after 5 days. He was discharged from the hospital after 2 weeks. 
DISCUSSION: Tetanus is caused by Clostridium tetani. The organism exists in two forms - spores and vegetative cells. Tetanospasmin is formed in the vegetative cells, under plasmid control that interferes with the inhibitory neurotransmitters, causing the trismus. There is no laboratory finding characteristic of tetanus. The diagnosis is entirely clinical and does not depend on bacteriological confirmation.

The incubation period of Tetanus is 3 to 21 days, and the shorter the incubation, the higher the risk of death. ${ }^{4}$ Most cases of Tetanus are following acute injury. There is also non-acute injury in IV drug users, persons with chronic wounds and complications of diabetes. ${ }^{5}$ Treatment is neutralization of tetanospasmin and care for muscle spasms. Human tetanus immunoglobulins (HTIG) neutralize the circulating tetanospasmin while the antibiotic combination kills the Clostridium tetani and super infected Staphylococci or Streptococci.

Although most cases of tetanus follow an acute penetrating skin injury, in some patients no portal of entry for the organisms can be identified ${ }^{2}$.More detailed history taking and recording is mandatory in the future so that important and complete data would be available for analysis, to provide invaluableinformation. ${ }^{6}$

CONCLUSION: Tetanus remains an important public health problem in India with substantial mortality and morbidity and affects unvaccinated and inadequately vaccinated individuals. It is entirely preventable by immunization. Our country has very limited resources and the continued occurrence of this preventable disease represents a drain on existing intensive care funds.

\section{REFERENCES:}

1. Schwartz E, Rodeisperger E (1990). Skin and soft tissue infections. In Schillinger D, HarwoodNuss A (eds.) Infections in emergency medicine. Vol. 2. New York; Churchill Livingstone, pp. 63113.

2. Farrar JJ, Yen LM, Cook T (2000). Neurological aspects of tropical disease J Neurol Neurosurg Psychiatry. 69: 292-301.

3. Bleck TP, Brauner JS. Tetanus (1997). In Scheld WM, Whitely RJ,Durack DT (eds.) Infections of the central nervous system. $2^{\text {nd }}$ ed. Philadelphia; Lippincott-Raven, pp. 629-53.

4. Cook TM, Protheroe RT, Handel JM. Tetanus: a review of the literature. Br J Anaesth 2001; 87:477-87.

5. Hsu SS, Groleau G (2001). Tetanus in the emergency department: Acurrent. JEM. 20:357-365.

6. Bowen V, Johnson J, Boyle J, Snelling CF Tetanus-A continuing problem in minor injuries. Can J surg1988; 31:7-9. 


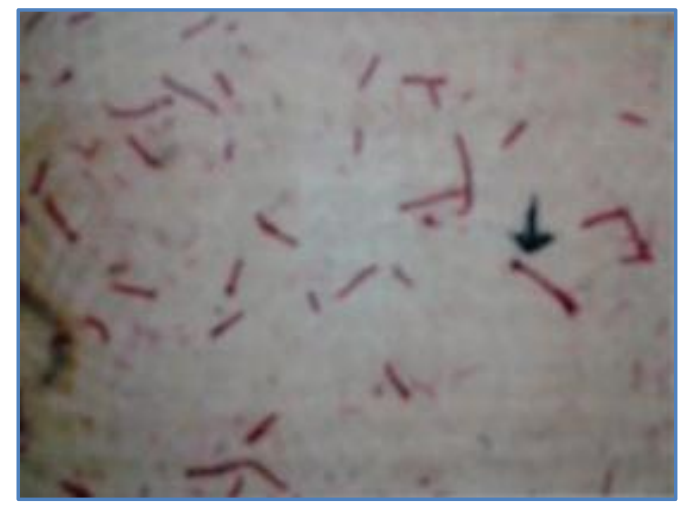

Fig. 1: Drum stick Clostridium tetani in the tissue of patient

\section{AUTHORS:}

1. Sreelatha P.

2. Shyam P.

3. Venkata Umakanth U. K.

4. Saswati Chattopadhyay

5. Raja Mukherjee

\section{PARTICULARS OF CONTRIBUTORS:}

1. Professor, Department of Microbiology, Mamatha General Hospital, Khammam, Andhra Pradesh.

2. Professor, Department of Dermatalogy, Mamatha General Hospital, Khammam, Andhra Pradesh.

3. Assistant Professor, Department of General Medicine, Mamatha General Hospital, Khammam, Andhra Pradesh.

4. Demonstrator, Department of Microbiology, IPGME \& R, Kolkata.
5. MO, Department of Orthopaedics, Durgapur SD Hosiptal, West Bengal.

\section{NAME ADDRESS EMAIL ID OF THE CORRESPONDING AUTHOR:}

Dr. Saswati Chattopadhyay, \#1, Amarnath Road, Uttarapara, Hoogly, West Bengal-712258.

Email: dr.saswathichattopadhyay@gmail.com

Date of Submission: 30/08/2014. Date of Peer Review: 01/09/2014. Date of Acceptance: 05/09/2014. Date of Publishing: 13/09/2014. 